\title{
Foucault-Kant e a questão da Aufklärung como maioridade pedagógica
}

Claudio A. Dalbosco

\section{RESUMO}

Este ensaio reconstrói, em largos traços, a interpretação que Foucault faz da Aufklärung kantiana. Procura mostrar, por um lado, que tal interpretação lhe serve de autoesclarecimento filosófico, isto é, como certificação da noção de filosofia como pensamento da atualidade. Por outro, que esta noção de filosofia nos torna produtiva a própria ideia de uma filosofia da educação baseada na Aufklärung como maioridade pedagógica.

\section{PALAVRAS-CHAVE}

Filosofia; Atualidade; Maioridade pedagógica

\section{Foucault-Kant and the Aufkrärung issue as a pedagogical majority}

\begin{abstract}
The essay rebuilds, in broad traces, the interpretation that Foucault draws from Kant's Aufklärung. It seeks to show, on one hand, that such an interpretation fits him as a philosophical self-clarification, i.e., as a certification of the notion of philosophy as a thinking of the actuality. On the other hand, it seeks to show that the notion of philosophy renders productive the very idea of a philosophy based on Aufklärung as a pedagogical majority.
\end{abstract}

KEYWORDS

Philosophy; Actuality; Pädagogische mündigkeit 
Não sei se é preciso dizer hoje que a tarefa crítica também implica a Aufklärung (esclarecimento); penso, em todo caso, que esta tarefa sempre exige um trabalho sobre nossos limites, isto é, um trabalho paciencioso que dá forma à impaciência da liberdade (FOUCAULT, 1990a, p. 53).

Aufklärung (esclarecimento) é a saída do homem de sua menoridade da qual ele mesmo é culpado. [...] Sapere aude! Tenha coragem de servir-se de seu próprio entendimento! Tal é a palavra de ordem da Aufklärung (KANT, 1998, VI, p. 53).

Maioridade (Mündigkeit) é a descoberta da base quasetranscendental da comunidade considerada como o que precisamos para a filosofia e para a dignidade humana (RABINOW; DREYFUS, 1990, p. 57).

\section{INTRODUÇÃO}

O pensamento do último Foucault, sobretudo aquele apresentado nos cursos oferecidos no Collège de France, nos anos finais antes de sua morte, ocorrida em 1984, pode tornar-se uma ferramenta conceitual indispensável para pensar criativamente a relação entre filosofia e educação. Ou seja, seu esboço de uma ontologia do presente pode nos auxiliar para esclarecer em que medida a filosofia possui uma base pedagógica, e a própria pedagogia, por sua vez, conteúdo filosófico. Obviamente, nem toda a filosofia e nem toda a pedagogia deixam-se ver nesta perspectiva de diálogo recíproco. Pelo contrário, como já tratamos em outro lugar (DALBOSCO, 2010, p. 179-210), uma filosofia concebida no sentido escolástico (Kant) e uma pedagogia tomada exclusivamente como uma ciência empírica (Brezinka) põem-se, de antemão, mutuamente, inúmeros obstáculos que dificultam ou anulam o diálogo entre ambas.

No entanto, considerando a importância disso para o aprofundamento da problemática educacional e para o próprio autoesclarecimento da filosofia, defendemos a hipótese, neste ensaio, de que o pensamento do último Foucault se torna produtivo e, até mesmo, indispensável, para pensar uma filosofia da educação transformada, que seja capaz de conceber a atualidade da problemática educacional também como uma tarefa filosófica. Pensamos, nesse sentido, que a interpretação de Foucault sobre a Aufklärung kantiana serve não só aos seus propósitos de fundar uma ontologia do presente, como também, ao mesmo 


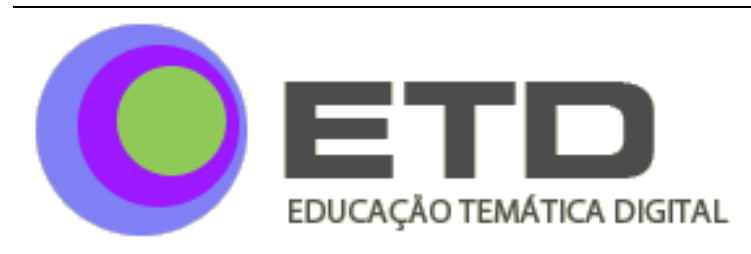

DOSSIÉ

tempo, para mostrar, exemplarmente, a profunda problemática formativo-educacional que está subjacente ao projeto do esclarecimento como maioridade (Aufklärung als Mündigkeit); e, por fim, serve à própria ideia de filosofia como atualidade.

No contexto deste ensaio, duas questões são decisivas: a) Em que termos a ontologia do presente se deixa justificar a partir da tese kantiana do esclarecimento como maioridade? b) Que aspectos pedagógico-educacionais estão vinculados com esta temática? O tratamento da primeira questão leva-nos a parafrasear, em largos traços, a interpretação que Foucault faz do artigo de Kant "Was ist Aufklärung?"; a segunda, a pensar as implicações pedagógicas que estão entrelaçadas com o tema. O enfrentamento de ambas terá como delimitação textual as duas primeiras aulas do curso proferido por Foucault no início de 1983 e publicado, posteriormente, com o título Le gouvernement de soi et des autres (O governo de si e dos outros).

\section{A AUFKLÄRUNG KANTIANA COMO BASE DA ONTOLOGIA DO PRESENTE}

O leitor que tivesse feito a experiência de passar diretamente da leitura de $A s$ palavras e as coisas (Les mots et les choses - 1966) para O governo de si e o governo dos outros (Le gouvernement de soi et des autres - 1982-1983), sem ter tido a oportunidade de ler outras obras de Foucault e de ter acompanhado sua evolução intelectual de quase duas décadas, ficaria perplexo, certamente, com um conjunto de coisas. Entre elas, com a passagem de um discurso que não só afirma, enfaticamente, o "fim do homem", como também se mostra cético em relação ao conteúdo e às realizações do pensamento iluminista moderno, sobretudo em relação à base epistêmica que o sustenta, para outro discurso, que procura resgatar, pelo menos, um núcleo central dessa tradição, a saber, o núcleo da Aufklärung

\footnotetext{
${ }^{1}$ Este tema certamente é um dos mais controversos em As palavras e as coisas. Na parte final do nono capítulo da referida obra, reportando-se explicitamente ao dito nietzschiano da morte de Deus, Foucault formula a expressão "morte do homem", afirmando que "o fim do homem é o retorno do começo da filosofia" (FOUCAULT, 1990b, p. 358). Desde então, tornou-se um grande problema compreender o que ele realmente quis dizer com a expressão "fim do homem". Parece-nos plausível interpretá-la, como o faz Ewald, enquanto uma crítica à tradição humanista e, especialmente, à postura filosófica que procura compreender o homem na perspectiva de um sujeito universal. Nesse sentido, a morte do homem significa o desaparecimento de um sujeito fundado, sujeito universal, indicando-se com isso, simultaneamente, que outra política é possível: uma política na qual a história não deve ser mais a história do sujeito, na qual o Estado não está mais no centro, mas, sim, as formas plurais e diversificadas de micropoderes. Para Ewald, a expressão "fim do homem" é resultado de uma filosofia como diagnose que, para poder sê-la, precisa transformar-se, imediatamente, em política (EWALD, 1990, p. 96).
} 


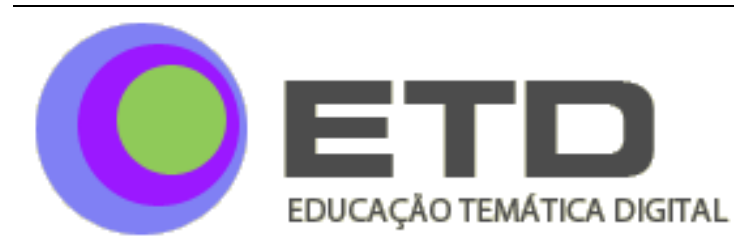

DOSSIÉ

kantiana, e empregá-lo para justificar sua ontologia do presente. O que teria levado Foucault, efetivamente, a reconsiderar aspectos significativos desta sua trajetória intelectual? Trata-se propriamente de uma ruptura entre uma etapa e outra? Estas, entre outras, são questões que surgem da ocupação com o pensamento do último Foucault.

Parece-nos, neste contexto, que a mudança na noção de filosofia é um indicativo importante para tratar das questões acima e, portanto, para compreender a própria reconsideração feita por Foucault sobre o Iluminismo moderno, especificamente, sobre a Aufklärung kantiana. A obra As palavras e as coisas localiza-se, nitidamente, no marco de uma epistemologia arqueológica e, embora pretenda fazer uma crítica à episteme clássica que estaria na base do nascimento das ciências humanas, desenvolve tal crítica amparando-se, em última instância, no conceito escolástico (Schulbegriff) de filosofia, para já empregar a terminologia kantiana. Sem ainda saber e, muito provavelmente, sem o querer, Foucault tem diante de seus olhos o modelo de crítica desenvolvido na Crítica da razão pura, designado por ele, mais tarde, já de forma plenamente consciente, como analítica da verdade. ${ }^{2}$ Então, é a noção de crítica como analítica da verdade que lhe oferece parte das referências conceituais necessárias para investigar a episteme das ciências humanas. O que se pode deduzir daí é que o próprio "projeto" de investigação arqueológica se insere, ele mesmo, de certo modo, ainda no âmbito da analítica da verdade.

Por analítica da verdade entende Foucault, anos mais tarde, já no contexto da Hermenêutica do sujeito, aquela investigação que se ocupa com as condições que tornam a verdade possível, sem tratar, no entanto, das transformações e dos deslocamentos necessários que o próprio sujeito precisa fazer para que possa ter acesso à verdade. ${ }^{3} \mathrm{O}$ que importa, muito

\footnotetext{
${ }^{2}$ Na verdade, como alerta Terra (2003, p. 176-177), pelo fato de estar "preso estritamente à camisa de força da arqueologia", Foucault vê-se impedido de compreender o projeto crítico de Kant em sua profundidade. No curso de 1982-1983, quando já está livre de tal camisa de força, ele pode, então, recuperá-lo e interpretá-lo numa outra perspectiva. Ao final de seu artigo (TERRA, 2003, p. 178), Terra sinaliza para a ideia, formulada em forma de questionamento, de que a contraposição entre analítica da verdade e ontologia do presente poderia ser vista como retomada da distinção kantiana entre Schulbegriff e Weltbegriff. Nesse sentido, como procuramos mostrar, brevemente, na sequência, a ontologia do presente de Foucault, ao apoiar-se na Aufklärung kantiana como pensamento da atualidade, tem como pano de fundo o conceito de filosofia como Weltbegriff.

${ }^{3}$ Trata-se aqui muito mais de uma verdade ligada à espiritualidade do que da verdade analítica, como Foucault esclarece, na primeira aula do curso de 1981-1982, publicado, posteriormente, com o título Hermenêutica do sujeito (L'herméneutique du sujet - 2001). Nesse curso, Foucault, colocando a filosofia entre aspas, compreende-a como "forma de pensamento que tenta determinar as condições e os limites do acesso do sujeito à verdade" (FOUCAULT, 2004, p. 19). A essa noção de filosofia, ele opõe a espiritualidade, a qual, por sua vez, dá origem a outra ideia de verdade. Assim afirma ele: "A verdade só é dada ao sujeito a um preço que põe em
} 


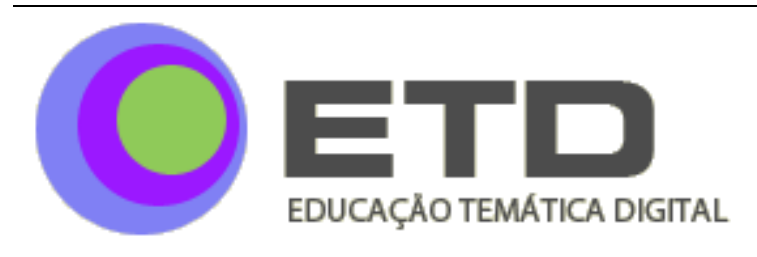

DOSSIÉ

mais a Foucault, agora, certamente, não é aquilo que a analítica da verdade propriamente é, mas sim o que ela exclui ou precisa deixar de fora de sua abordagem para poder constituir-se enquanto tal, isto é, como analítica. O aspecto por ela ignorado - ou seja, todas as transformações que o sujeito precisa fazer para que possa aceder à verdade -, é o processo de subjetivação que está na base da ontologia de nós mesmos, a ser conquistada pelas diferentes formas da pragmática de si. O fato é que tudo isso pressupõe já outra noção de filosofia, a qual tem muito mais a ver com o Weltbegriff (conceito de mundo) do que com a Schulbegriff.

Kant faz esta distinção no final da Crítica da razão pura (1998, B, p. 866-887), onde define a Schulbegriff como "o conceito de um sistema de conhecimento que só é procurado como ciência" e o Weltbegriff (conceptus cosmicus) como "fundamento do termo 'filosofia". Estes dois conceitos servem-lhe para definir a filosofia como "ciência da relação de todo o conhecimento ao fim essencial da razão humana" e o filósofo "não como um arquiteto da razão humana, mas sim como seu legislador” (KANT, 1998, II, p. 700). O ponto que nos interessa é que Kant defende, já na Crítica da razão pura, a ideia de que, para o filósofo ser o legislador da razão humana, ele precisa compreender a filosofia como conceptus cosmicus, isto é, tomá-la como forma de viver e, por isso, acrescentaríamos nós, de ser capaz de refletir também sobre o sentido da existência humana.

Mas, por ainda estar excessivamente influenciado pela perspectiva estruturalista ${ }^{4}$, o Foucault das Palavras e as coisas extrai da Crítica da razão pura somente o que é útil aos seus propósitos imediatos e, com isso, deixa de lado ou não dá a devida ênfase para outros aspectos que não só serão desenvolvidos pelo próprio Kant, como também se tornarão decisivos para as ideias tardias de Foucault. É nesse contexto, que outro Kant, aquele dos escritos menores, muito menos escolástico, é chamado por Foucault para avalizar a noção de filosofia como ocupação com o presente - como reflexão sobre a atualidade - e, portanto, para

jogo o ser mesmo do sujeito. Pois tal como ele é, não é capaz de verdade. Acho que esta é uma forma mais simples, porém, mais fundamental para definir a espiritualidade" (FOUCAULT, 2004, p. 20). Portanto, o saber de espiritualidade permite uma ampliação da questão da verdade, fazendo com que às condições e aos limites da verdade sejam agregadas também, como um aspecto fundamental e, talvez, primeiro, as transformações que o sujeito precisa passar para que possa ter acesso à verdade. Estas transformações constituirão o sentido "espiritual" de verdade que está na base da pragmática de si e da ontologia do presente abordadas no curso seguinte, dos anos de 1982-1983.

${ }^{4}$ Rabinow e Dreyfus mapeiam o panorama intelectual marcado pela disputa metodológica entre estruturalismo e hermenêutica, no qual emergiram os primeiros trabalhos de Foucault. Embora defendam que Foucault nunca tenha sido "um estruturalista estritamente falando, ou um pós-estruturalista", ele teria compartilhado de "alguns pressupostos fundamentais com a abordagem estruturalista” (RABINOW; DREYFUS, 1995, p. xx-xxi). 


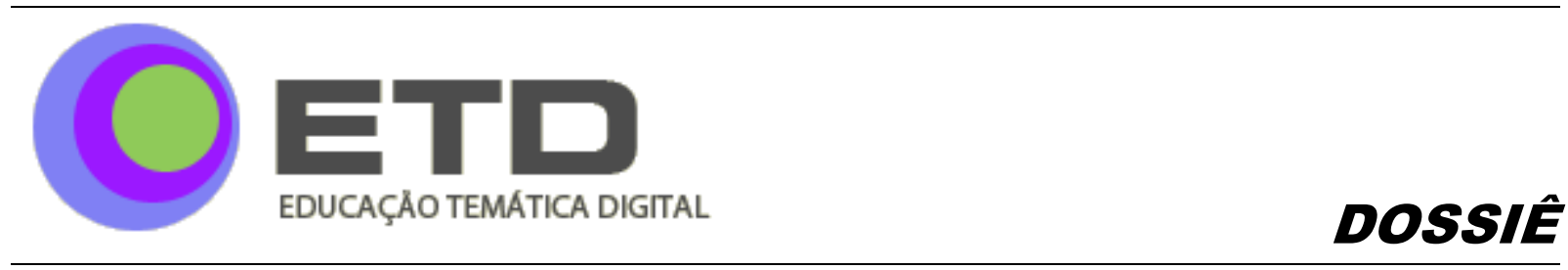

esclarecer a própria ontologia do presente e sua pragmática de si.

Constatamos, com isso, que somente depois de um longo percurso intelectual, no qual consolida e dá prosseguimento a algumas ideias e reconsidera outras, é que Foucault chega à pragmática de si. Na primeira hora da primeira aula do curso de 1983 - aula do dia 5 de janeiro -, oferece um resumo esquemático de sua própria trajetória intelectual, destacando o núcleo investigativo percorrido até chegar à pragmática de si. Adverte, antes de tudo, que sob a rubrica "história do pensamento" buscou diferenciar-se, metodologicamente, tanto da "história das mentalidades" como da "história das representações", concentrando sua atenção no "foco da experiência", articulando-o em três aspectos: nas "formas de um saber possível, [nas] matrizes normativas de comportamento [e nos] modos de existência virtuais para sujeitos possíveis" (FOUCAULT, 2009, p. 19). Ora, são esses três aspectos que, segundo ele, viriam a constituir, progressivamente, os três eixos temáticos que definiriam sua própria trajetória intelectual posterior.

O que nos chama a atenção, antes de tudo, no resumo oferecido por Foucault, nesta primeira aula, é a insistência no emprego da expressão "deslocamento", sem que outras expressões, como "ruptura" ou "descontinuidade" sejam referidas. A pergunta que surge reporta-se, evidentemente, ao sentido da expressão "deslocamento". A meu ver, ela assume uma dupla significação: uma esclarecida pelo próprio Foucault; e, outra, subjacente, mas decisiva para compreender sua trajetória intelectual como um projeto contínuo, caracterizado por um maior aprofundamento teórico, a cada vez que ele passa de um eixo ao outro. Contudo, a primeira significação assinala o deslocamento que ocorre no interior de cada eixo, de uma temática "tradicional' para uma nova: do conhecimento ao saber; do poder como instituição ("Poder" com maiúscula) ao poder como condução ou governo (referente, basicamente, à ideia de governamentalidade); e, por último, da subjetividade à pragmática de si. A segunda significação, implícita ao próprio resumo de Foucault, torna-nos clara a presença de certo fio condutor que se mantém, não só no deslocamento ocorrido no interior de cada eixo, mas também na passagem de um eixo ao outro.

Se isto é assim, então não há, como se poderia supor, uma rachadura sem concertos na sua trajetória intelectual, que caracterizaria o total abandono de temas e de perspectivas teóricas e a sua substituição por algo inteiramente novo. Portanto, esse modo de 
compreender o percurso intelectual de Foucault nos desautoriza a ver na "arqueologia", na "genealogia" e na "pragmática de si" três projetos (eixos) teóricos absolutamente estanques entre si, segundo os quais a passagem de um ao outro significaria uma ruptura teórica intransponível.

Voltemo-nos, neste instante, para o resumo oferecido por Foucault sobre os três eixos de seu percurso intelectual. O primeiro eixo consiste no estudo da formação dos saberes, tomando as ciências empíricas (história, gramática geral, economia, etc.) como exemplo da análise. Trata-se aí de um deslocamento da história do conhecimento para a análise dos saberes, considerando as práticas discursivas que os estruturam. O próprio Foucault resume o percurso empreendido no primeiro eixo do seguinte modo: "Do conhecimento ao saber, do saber às práticas discursivas e às de veridição: tal era o deslocamento que durante um tempo procurei efetuar" (FOUCAULT, 2009, p. 20). Decisivo aqui é o deslocamento da problemática do conhecimento para o saber: a própria noção de saber já deveria conter, então, intuições originárias que se tornariam cada vez mais claras, ganhando concatenações concretas ao alcançar a pragmática de si. Nesse sentido, o deslocamento do conhecimento para o saber não significa somente o abandono de uma temática "tradicional", marcada pela analítica da verdade, mas, sim, quando visto retroativamente, na perspectiva da trajetória intelectual de Foucault, o prenúncio da futura recusa explícita de tal analítica e, simultaneamente, a justificativa em germe da pragmática de si.

O segundo eixo procura investigar as matrizes normativas de comportamento, concentrando-se na análise "das técnicas e dos procedimentos por meio dos quais se pretende orientar a conduta dos outros" (FOUCAULT, 2009, p. 21). O que está em jogo nesta investigação é a questão da norma de comportamento concebida em termos de poder, o qual é compreendido, por sua vez, não como instituição e, muito menos, como objeto, mas, sim, como exercício; isto é, como uma arte de governar. Portanto, com a expressão "matrizes normativas de comportamento", Foucault busca desvelar a relação estreita entre norma, poder e governo, tomando a dinâmica tensional que se estabelece em tal relação como constitutiva da ação humana e de sua própria sociabilidade. Ele descreve, assim, o deslocamento ocorrido neste segundo eixo temático: "passar da análise da norma ao do exercício do poder e deste aos procedimentos de governamentalidade" (FOUCAULT, 2009, p. 21). Se, antes, no eixo 


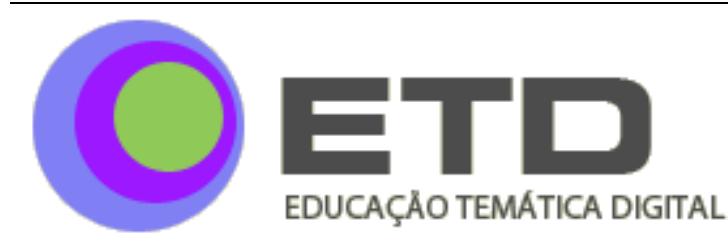

DOSSIÉ

anterior, o deslocamento do conhecimento para o saber continha algo de originário que permitiu a Foucault não assumir inteiramente um procedimento em termos de analítica da verdade, agora, neste segundo deslocamento, a recusa do Poder com maiúscula significa a posição de algo inteiramente novo, a ser preservado pelo terceiro eixo; a saber, a noção positiva de poder como forma de condução ou governo. Ou seja, em síntese, é a questão da governamentalidade ${ }^{5}$ que o conduz à pragmática de si.

Por fim, o terceiro eixo, o qual diz respeito à constituição do modo de ser do sujeito. Ele é decisivo para os nossos propósitos, porque é para legitimá-lo ou, pelos menos, para explicitá-lo que Foucault recorre ao texto kantiano "Was ist Aufklärung?". Dito de outro modo, a exegese do texto kantiano deve servir-lhe para esclarecer o deslocamento que ocorre neste eixo temático. Trata-se aqui, como ele mesmo anuncia, do deslocamento de uma teoria do sujeito para a análise das diferentes formas que impelem o indivíduo a conceber-se como sujeito. Ou seja, existem determinadas condutas assumidas pelos indivíduos em determinadas situações, como, por exemplo, no comportamento sexual, que podem conduzi-los a constituirse como sujeito moral. ${ }^{6}$ Seu interesse consiste aí em analisar o modo e as formas concretas empregadas pelo indivíduo na relação consigo mesmo, para colocar-se a exigência de se tomar como sujeito moral. Em resumo, trata-se de "passar da questão do sujeito para a análise das formas de subjetivação, concebendo-as por meio das técnicas/tecnologias da relação consigo mesmo ou, se preferirem assim, do que se pode denominar de pragmática de si” (FOUCAULT, 2009, p. 21). Portanto, tem-se aí a fundação da pragmática de si, a qual exige que o foco se desloque da teoria do sujeito para as formas de subjetivação; e, para testemunhar tal deslocamento, Foucault reporta-se à Aufklärung kantiana de 1784.

\footnotetext{
${ }^{5}$ Foucault trata deste tema, originariamente, na perspectiva futura de uma pragmática de si na quarta aula do curso de 1977-1978, intitulado "Segurança, território e população". Nesta aula do dia 01 de fevereiro de 1978, ele procura analisar a passagem das questões de soberania para as questões de governo, tomando como referência o longo período histórico que vai do século XVI ao XIX. Nesse contexto, pontualiza os problemas que lhe interessarão mais tarde, da seguinte forma: "Como governar-se, como ser governado, como governar os outros, por quem devemos aceitar ser governados, como fazer o melhor governo possível” (FOUCAULT, 2006, p. 282). O que é oferecido nesta aula como "formulações sobre a instalação deste fenômeno chamado governamentalidade" (FOUCAULT, 2006, p. 305) será aprofundado no curso de 1982-1983 sob a ótica do governo de si e do governo dos outros. Nesse contexto, para uma apresentação geral e introdutória do pensamento de Foucault, contemplando, sobretudo, o problema da governamentalidade e seu vínculo com a educação, ver o estudo de Veiga Neto (2003).

${ }^{6}$ São estas preocupações que o conduzem a estudar a história da sexualidade, publicada, posteriormente, em três volumes.
} 


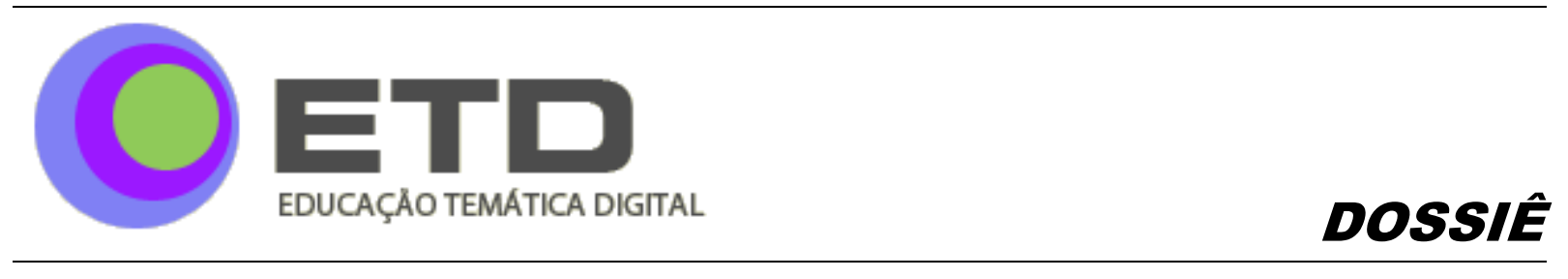

Com este breve resumo da trajetória intelectual de Foucault, estamos agora em melhores condições de analisar a influência que Kant exerce no terceiro eixo. Se, por um lado, como vimos acima, o modelo de crítica inspirado na Crítica da razão pura abre para Foucault um amplo leque investigativo, oferecendo-lhe as bases "transcendentais" para desenvolver a arqueologia da episteme das ciências humanas, por outro, limita-o, claramente, a um determinado conceito de filosofia e, obviamente, cega-o para outros. Nesse sentido, com Foucault contra Foucault, poderíamos dizer que As palavras e as coisas apoia-se na "filosofia crítica", mas ainda se ressente de um "pensamento crítico", o qual ganhará corpo somente mais tarde, a partir do terceiro eixo. Tal pensamento exigirá outra ideia de filosofia, que se tornará mais clara na exegese foucaultiana do ensaio de Kant "Was ist Aufklärung?".

Mas o que há de significativo neste ensaio de Kant para os propósitos derradeiros de Foucault? Que nova ideia de filosofia e de crítica encontrará aí e em que sentido toma tais noções para esclarecer sua própria ontologia do presente? Um estudo pormenorizado da livre exegese de Foucault sobre o texto kantiano deveria concentrar-se na riqueza de detalhes que ela contém e, ao mesmo tempo, na análise de seus aspectos problemáticos. Infelizmente, como não podemos fazer isso agora, limitamo-nos apenas a parafraseá-la, no que se refere, especificamente, à noção de filosofia; e, para fazê-lo, precisamos, evidentemente, reportar-nos às noções de esclarecimento e de maioridade.

Foucault faz um primeiro ingresso no texto kantiano "Was ist Aufklärung?" ainda na parte final da primeira hora da aula do dia 5 de janeiro, reservando para a segunda hora uma abordagem mais sistemática. Neste primeiro ingresso, ele já pontua as diretrizes gerais de sua exegese, detendo-se na análise do significado que o lugar e a data da publicação do escrito possuem. Para o fato de Kant ter publicado o texto em 1784, numa Revista (na Berlinische Monatsschrift), Foucault atribui quatro razões distintas:

a) Kant concebe a questão da Aufklärung como meio de formação de um público (Publikum), analisando a relação entre o escritor (como homem de cultura) e o leitor que lê. Isso é indicativo, então, de um modo de formação da opinião pública, usual na Alemanha da segunda metade do século XVIII, que não ocorria diretamente na universidade, mas, sim, nas 
sociedades e nas academias, as quais, com suas respectivas revistas, propiciavam o encontro entre escritor e leitor na forma livre de circulação do discurso escrito (FOUCAULT, 2009, p. 25).

b) A pergunta "Was ist Aufklärung?" não era exclusividade kantiana e nem fora abordada somente por Kant. Fora tratada também, entre outros, por Mendelssohn ${ }^{7}$ e, sob este aspecto, representa o encontro entre duas tradições, a Aufklärung cristã e a judaica (Haskalá). Nesse sentido, o que estes dois autores afirmam em comum é a necessidade da liberdade absoluta para o exercício da religião, considerado como algo privado. Na verdade, o próprio Kant destaca esta posição de Mendelssohn, defendida em Jerusalém, de que a religião deveria ser só de uso privado, vendo nela um bom exemplo a ser seguido por todos os cristãos: tal posição deveria ser útil para a atitude que todo cristão deveria assumir em relação a sua própria religião (FOUCAULT, 2009, p. 28).

c) O texto "Was ist Aufklärung?" torna-se interessante porque apresenta um novo tipo de questão no campo da reflexão filosófica, referente ao presente e à atualidade, deixando-se resumir pelas seguintes perguntas: O que está ocorrendo hoje? O que está acontecendo na atualidade e que se torna relevante para a reflexão filosófica? Mais ainda, e esta é a radicalidade que a pergunta kantiana parece exigir, o que é precisamente este presente ao qual pertenço? Assim conclui Foucault: "Em resumo, me parece que no texto de Kant vemos surgir a questão do presente como acontecimento filosófico ao qual pertence o filósofo que dele fala" (FOUCAULT, 2009, p. 30). Ora, o que interessa a Foucault neste texto é que, ao se debruçar sobre o presente como acontecimento filosófico, o filósofo nada mais faz do que tomar a si mesmo como parte de um "nós outros". Portanto, ao colocar-se a questão sobre a atualidade e para poder interrogar-se sobre ela, o filósofo precisa conceber-se como interligado a outros, isto é, pertencente à humanidade.

d) Por fim, a quarta razão que justifica a importância deste texto de Kant consiste, segundo Foucault, no fato de que ele revela certa maneira de filosofar que vai muito além da época da Aufklärung. Isso significa dizer que a concepção kantiana de filosofia como

\footnotetext{
${ }^{7}$ Como esclarece Bahr, no posfácio da coletânea sobre "Was ist Aufklärung?", na qual reúne pequenos textos de autores importantes da época, que se envolveram no amplo debate sobre a Aufklärung alemã, Mendelsohn significou para o judaísmo alemão, durante décadas, o símbolo de uma ligação bem-sucedida entre judaísmo e Aufklärung e, portanto, o símbolo da emancipação judaico-alemã (BAHR, 1996, p. 75).
} 


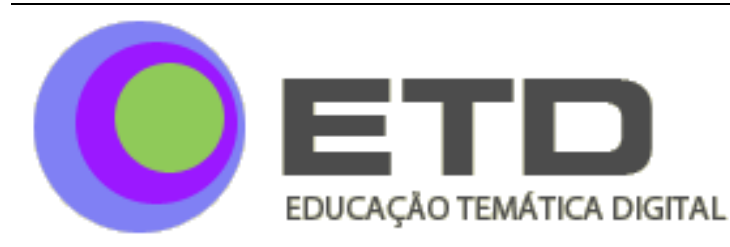

DOSSIÉ

indagação da atualidade não permanece restrita somente ao âmbito da filosofia moderna, mas alastra-se para os séculos seguintes, chegando com força até os dias atuais. "Poderíamos seguir toda a trajetória dessa questão da filosofia que se interroga sobre sua própria atualidade através do século XIX e já desde o século XVIII” (FOUCAULT, 2009, p. 32-33). ${ }^{8}$

De acordo com esse resumo acima, o primeiro ingresso introdutório de Foucault ao texto kantiano "Was ist Aufklärung?" faz surgir, como resultado principal, também para nossos propósitos, a noção de filosofia como ocupação com o presente, isto é, como reflexão sobre a atualidade. Esta questão diferencia-se, nitidamente, para Foucault, daquela outra, também fundada por Kant, principalmente na Crítica da razão pura, sobre as condições de possibilidade do conhecimento e que é desenvolvida na forma de analítica da verdade. Desse modo, Foucault vê em Kant o fundador de duas grandes vertentes da filosofia moderna, as quais, ao se desenvolver, tomarão direções distintas: uma, como analítica da verdade e outra, como reflexão sobre a atualidade. Aqui não surpreende o fato de Foucault não só apregoar a necessidade atual de uma eleição filosófica, como também, obviamente, optar, ele mesmo, pela noção de filosofia como reflexão da atualidade, ou seja, como reflexão sobre "qual é o campo atual das experiências possíveis?” (FOUCAULT, 2009, p. 39).

Em síntese, o comentário introdutório de Foucault já nos permite ver em que sentido o texto kantiano "Was ist Aufklärung?" serve para seu próprio autoesclarecimento filosófico. Ou seja, em que sentido a noção kantiana de filosofia como ocupação com a atualidade leva-o a definir sua própria ontologia do presente. A Aufklärung kantiana possui, como vimos, dois traços distintivos: a) é um tipo de reflexão que se debruça sobre a atualidade; b) e, para poder fazê-lo, precisa incluir o outro por meio da consideração de si mesmo. Neste movimento de pensamento tripartite - reflexão sobre a atualidade, inclusão dos outros e consideração de si mesmo -, extraído da Aufklärung kantiana, Foucault encontra os traços principais para conceber sua ontologia do presente como ontologia de nós mesmos. ${ }^{9}$

\footnotetext{
${ }^{8}$ Além da questão da Aufklärung, Foucault analisa a posição de Kant sobre a Revolução Francesa, tomando-a também como forma de legitimação da questão da filosofia como reflexão da atualidade. Por considerar como suficientes, para os nossos propósitos, os resultados obtidos da análise foucaultiana do texto "Was ist Aufklärung?", dispensamo-nos agora de reconstruir seu comentário sobre a posição kantiana acerca da Revolução Francesa.

${ }^{9}$ A ontologia do presente e a ontologia de nós mesmos formam, segundo Rabinow e Dreyfus, as duas dimensões da ontologia crítica de Foucault. Tais dimensões possuem, por sua vez, dois componentes que, embora separados, pertencem um ao outro: o trabalhar sobre si mesmo e o responder ao seu próprio tempo (RABINOW;
} 
Como podemos observar, trata-se de uma ontologia de nós mesmos que só se pode constituir enquanto tal porque é reflexão sobre a atualidade concebida como pensamento sobre os outros, considerados como nós mesmos. Com isso, Foucault parece resgatar uma tarefa eminentemente prática para a filosofia: como crítica social, como visualização conceitual de alternativas possíveis, feita em companhia com os outros e - como resultado maior para quem propriamente se interroga sobre a atualidade -, como esclarecimento de si mesmo.

Portanto, e esta é a ideia conclusiva importante deste tópico, o questionamento da filosofia sobre a atualidade conduz para a reflexão sobre nós mesmos. Se este é o resultado alcançado até aqui, cabe-nos ainda interrogar: o que significa este "nós mesmos" e que problemática pedagógica ele carrega? Na sequência, trataremos desta questão parafraseando a exegese foucaultiana do texto "Was ist Aufklärung?", feita na segunda hora da aula de 5 de janeiro de 1983. Em princípio, a ideia da Aufklärung como Mündigkeit parece revelar-se uma pista esclarecedora, porque vai nos mostrar que este "nós mesmos" compreendido na perspectiva do "governo de si" precisa também ser formado pelo "governo dos outros". É esta mútua dependência entre governo de si e governo dos outros que, na medida em que exige um processo formativo-educacional, autoriza-nos a falar de um primado pedagógico inerente à questão da Aufklärung como maioridade. Este será, a seguir, o nosso tema.

\section{A AUFKLÄRUNG COMO MÜNDIGKEIT PEDAGÓGICA}

Foucault faz da análise do primeiro parágrafo do texto "Was ist Aufklärung?”, de Kant, na segunda hora da referida aula, motivos de muitos e longos comentários. Para o ponto que nos interessa, cabe destacar, em primeiro lugar, o comentário sobre a expressão Ausgang ("saída"). A análise desta expressão serve-lhe para uma dupla finalidade: primeiro, para mostrar o grau de dificuldade que está inerente à compreensão do que Kant realmente quis dizer quando definiu a Aufklärung como "saída do homem de sua menoridade"; segundo, para

DREYFUS, 1990, p. 58). Nesse sentido, enquanto a ontologia do presente conduz necessariamente para uma diagnose de época - e é isto que caracteriza a filosofia como pensamento da atualidade -, a ontologia de nós mesmos exige o trabalho do indivíduo sobre si mesmo, ou seja, o governo de si. Contudo, como buscaremos esclarecer na sequência, a questão do trabalho de si carrega uma exigência pedagógica que está na base do processo da Aufklärung como maioridade. 
destacar que a Aufklärung não significa nem pertença, nem imanência, nem, muito menos, consumação, mas, sim, Ausgang, ou seja, uma "saída" que envolve a ideia de movimento e de processo. Definida como saída, a Aufklärung engloba três expressões, às quais Foucault se refere em forma de perguntas: o que é menoridade? Quem é o homem que deve sair do estado de menoridade? E o que significa propriamente saída? Portanto, mesmo considerando a dificuldade da definição kantiana da Aufklärung como "a saída o homem de sua menoridade da qual ele próprio é culpável” (KANT, 1998, VI, p. 53), sua compreensão exige a análise destas três questões, sendo esta a tarefa assumida por Foucault na sequência de sua interpretação.

Das três questões acima, como é a menoridade (Unmündigkeit) a que mais nos interessa, pois é ela que nos conduz ao centro do significado da Aufklärung e da contribuição que a interpretação de Foucault traz, indiretamente, para o campo pedagógico, devemo-nos debruçar sobre ela. Foucault esforça-se para mostrar, em detalhes, que o estado de menoridade, ao qual Kant se refere, não significa uma impotência natural, nem uma imposição jurídica e política, mas, sim, é resultado de uma atitude ou maneira adotada pelo próprio indivíduo. Nesse sentido, cada um destes aspectos merece um breve comentário.

A menoridade não pode ser confundida com uma impotência natural, porque com ela Kant não quer expressar, segundo Foucault, algo como a infância da humanidade, pois isso conduziria à suposição de que o homem ou, pelo menos, parte da humanidade, seria incapaz de alcançar a maioridade. Ao contrário disso, Kant parte da convicção de que todos os homens são, em princípio, capazes de conduzir-se por si mesmos e, portanto, são capazes de alcançar a maioridade, fazendo uso de sua própria razão.

De outra parte, a menoridade também não é devida única e exclusivamente à imposição de vontades externas. Nesse sentido, se ela não é uma impotência natural, também não pode ser compreendida só como resultado da interferência de forças externas. Isso significa dizer que seu estado deve-se, inicialmente, não à culpa de outros; e é isso que Kant quer deixar claro, quando afirma que a menoridade é culpa do próprio homem. Foucault esclarece, neste contexto, que não se trata de uma privação de direito; portanto, o estado de menoridade não pode ser compreendido como uma imposição jurídica ou política. 
Com isso, fica clara a intenção de Foucault: mostrar inicialmente o que a menoridade não é, para, na sequência, seguindo as pegadas de Kant, dizer o que ela propriamente é. Se ela não é uma impotência natural, nem uma imposição de outros, o que ela efetivamente é? Se é um estado do qual o próprio homem é culpado, o que isso significa? Em que termos o homem é culpado? Com estas questões nos aproximamos não só do centro de interesses da interpretação foucaultiana, mas também, ao mesmo tempo, dos interesses de nossa própria paráfrase.

Kant emprega, em seu ensaio, três exemplos para caracterizar o estado de menoridade do qual cada um é culpado: o livro assume o lugar do entendimento; o diretor de consciência substitui a consciência moral de cada um; e, por fim, o médico prescreve e decide o regime ao paciente. Isso não significa dizer, obviamente, que Kant, ao utilizar estes exemplos, estivesse desconsiderando a importância de cada um daqueles agentes. Ao contrário disso, como afirma Foucault: "Jamais considerou ilegítimo que tivesse livros e que os mesmos fossem lidos. Nem se quer que fosse ilegítimo ter um diretor de consciência (Seelesorge) e, tão pouco, recorrer a um médico" (FOUCAULT, 2009, p. 46). O problema reside, mais propriamente, na maneira ou na postura que o indivíduo adota diante destas autoridades. Este é exatamente o ponto: não sendo impotência natural, nem imposição de outro, a menoridade é o estado do qual cada um é culpado, e isto porque ela diz respeito, antes de tudo, à maneira e à atitude com que cada um se posiciona frente à situação; no caso do exemplo de Kant, frente ao livro, ao diretor de consciência e ao médico. Colocando-se na posição de subserviência e submissão, torna-se menor; se visa sua maioridade, precisa postarse de maneira diferente.

A esta altura, a exegese de Foucault atingiu o ponto decisivo para sua pragmática de si, a saber: a Aufklärung kantiana conduz, como exercício filosófico de crítica da atualidade, à compreensão da menoridade como resultado de um estado de preguiça e de covardia do próprio indivíduo: ele é menor, antes de tudo, porque não possui a coragem necessária para fazer uso de sua própria razão! A interpretação do texto kantiano mostra a Foucault, portanto, num primeiro momento, que a Aufklãrung, como saída da menoridade para a maioridade, exige um voltar do indivíduo para si mesmo, para a consciência de sua condição de menor, tomando-a como algo que é, em parte, devido à sua própria 
responsabilidade. Nesse sentido, poderíamos dizer que a primeira condição de possibilidade para que ele possa alcançar o estado de maioridade é a consciência de que se encontra no estado de menoridade e de que ele próprio é, quando preguiçoso e covarde, responsável por tal estado.

Quando se pensa, por exemplo, no processo formativo-educacional de novas gerações, a Ausgang da qual fala Kant e o modo como Foucault a interpreta exigiriam, certamente, todo um trabalho pedagógico do indivíduo sobre si mesmo, para tomar consciência de sua condição de menoridade e para admitir sua própria parcela de culpa, no que diz respeito a tal condição. Este é, nitidamente, o primeiro aspecto da dimensão pedagógica que está estritamente relacionada com a problemática da Aufklärung como maioridade: trabalho pedagógico sobre si mesmo, cultivo de si mesmo. Mas há outro aspecto, que só poder ser compreendido na medida em que avançarmos na reconstrução da exegese de Foucault, sem o qual o primeiro aspecto ficaria incompleto ou até mesmo não seria possível. $\mathrm{O}$ segundo aspecto refere-se ao fato de que o trabalho ético-pedagógico do indivíduo sobre si mesmo exige a presença do outro, pela simples razão de que, do ponto de vista pedagógico, o indivíduo não adquire sozinho a consciência de sua menoridade. Isso está relacionado ao modo como Foucault concebe, filosoficamente, a saída da menoridade para a maioridade como sendo, no fundo, um problema da relação entre o governo de si e o governo dos outros. Nesse sentido, o problema do processo da Aufklärung como maioridade deixa-se resumir pela relação entre governo de si e governo dos outros; e pensar essa relação como um problema de atualidade consiste concebê-la, criticamente, como uma relação viciada em sua origem.

Não podemos levar adiante a análise deste segundo aspecto, sem antes considerar, ainda que brevemente, a relação que Foucault estabelece entre a Aufklärung e a noção de crítica. ${ }^{10} \mathrm{Na}$ verdade, para ele há uma estreita relação entre o projeto crítico kantiano,

\footnotetext{
${ }^{10}$ Em seu artigo, "What is Enligthenment?", Foucault afirma que a Aufklärung deve se traduzir num êthos filosófico compreendido como "crítica do que dizemos, pensamos e fazemos, por meio de uma ontologia histórica de nós mesmos" (FOUCAULT, 1990a, p. 48). Na sequência, ele define crítica como "análise dos limites e a reflexão sobre eles". E se, para Kant, a questão era estabelecer os limites do próprio conhecimento, agora, tal questão deve ser revertida, positivamente, em saber o que é contingente e arbitrário daquilo que nos é apresentado como universal. Assim afirma ele: "Resumindo, trata-se de transformar a crítica exercida na forma de uma limitação necessária para uma crítica prática mediante a forma de uma transposição possível" (FOUCAUlT, 1990a, p. 48). Portanto, o que em Kant aparecia como crítica do conhecimento, agora, em Foucault, é transformado numa crítica prático-política. É justamente essa transformação que caracteriza a pergunta central de sua ontologia do presente, a saber, "qual é o campo atual das experiências possíveis?".
} 


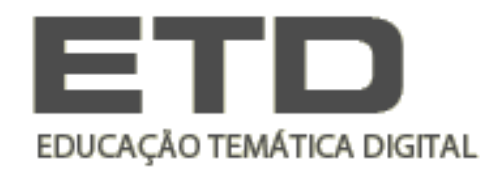

DOSSIÉ

elaborado sistematicamente nas três Críticas, e o processo da Aufklärung ${ }^{11}$. Embora possa existir um caráter forçoso nessa relação, o importante é que, com ela, Foucault pode estabelecer o vínculo, tão indispensável para seus propósitos, entre o uso que podemos dar à nossa razão e a direção de outros. Ou seja, ele retém do projeto crítico kantiano a questão que, segundo ele, interessava verdadeiramente a Kant, a saber, qual é o melhor emprego possível que podemos fazer de nossas forças inteligentes, colocando tal questão diretamente em relação com o problema do processo da Aufklärung. A partir disso, Foucault chega, então, à seguinte conclusão: "Governo de si, governo dos outros: o estado de menoridade se caracteriza sem dúvida nesta relação viciada. [...] E, por conseguinte, o que a Aufklärung deverá fazer, o que está fazendo, é justamente redistribuir as relações entre governo de si e governo dos outros" (FOUCAULT, 2009, p. 49).

Há duas ideias desta passagem que merecem ser analisadas em detalhes. A primeira refere-se à expressão "relação viciada". Podemo-nos perguntar: em que termos a relação entre governo de si e governo dos outros é uma relação viciada? Foucault não esclarece explicitamente este problema. No entanto, como se trata de uma questão-chave para definir sua ideia de filosofia como pensamento crítico da atualidade, podemos inferir, ao menos, duas indicações: a) o que caracteriza uma relação viciada pela ótica do governo de si é o fato de o indivíduo considerar-se a si mesmo covarde e preguiçoso e, quando age assim, deixar-se dominar facilmente pelos outros. Isso nos dá a ideia de que o pensamento crítico de que fala Foucault exige que o indivíduo sempre se coloque na situação em jogo e se

\footnotetext{
${ }^{11}$ Talvez esteja aí, nesta relação entre o projeto crítico kantiano e o processo da Aufklärung, um dos pontos mais problemáticos da exegese de Foucault. Ele estabelece uma relação esquemática e breve do livro, do diretor de consciência e do médico - que são os três exemplos aludidos por Kant para caracterizar a postura de menoridade do indivíduo -, respectivamente, com cada uma das três Críticas. No caso específico da relação entre o livro e a Crítica da razão pura, coloca-se, segundo Foucault, a questão do Verstand (entendimento). A familiaridade (semelhança) entre o projeto crítico e o processo da Aufklärung se daria no fato de ambos implicarem um exame crítico da razão pra estabelecer o uso que lhe é legítimo. No entanto, por ser muito esquemática e breve, a interpretação de Foucault não considera a diferença técnica estabelecida por Kant, na Crítica da razão pura, entre Verstand e Vernunft, concebendo-os como dois domínios distintos da razão pura e atribuindo-lhes tarefas diferentes e específicas. Se tivesse considerado tal diferença, Foucault poderia ter feito um uso mais produtivo desta distinção kantiana, o que certamente lhe daria mais força argumentativa para diferenciar sua pragmática de si da analítica da verdade, pois, enquanto esta última está baseada no emprego do Verstand, a pragmática de si apoia-se na Vernunft kantiana e, sobretudo, no conceito de filosofia como Weltbegriff (conceptus cosmicus). O que fica claro disso para o nosso ponto é que o processo da Aufklärung como maioridade sustenta-se no conceito de razão derivado da noção de filosofia como conceito de mundo. No entanto, é preciso considerar que o próprio Kant não foi rigoroso, muitas vezes, no emprego desta terminologia, pois, se tivesse sido, não poderia ter afirmado, como o fez no ensaio "Was ist Aufklärung?", que é preciso ter "a coragem de fazer uso de seu próprio entendimento", mas, sim, de ter "a coragem de fazer uso de sua própria razão". Ou seja, para ser coerente com a problemática implicada no processo da Aufklärung, deveria ter empregado a expressão Vernunf e não Verstand.
} 
autoavalie em relação ao processo da Aufklärung; b) pela ótica do governo dos outros, quando eles tomam como sua tarefa legítima o governo autoritário sobre o indivíduo. O pensamento crítico exigiria aqui a ruptura com qualquer tipo de autoritarismo. Temos, assim, caracterizadas, duas situações limites que precisam ser superadas para que o processo da Aufklärung se transforme em maioridade. Estas duas situações possuem, como ficará explícito logo abaixo, implicações de natureza não só política, mas também pedagógica.

A segunda ideia da passagem refere-se à expressão "redistribuir as relações". Esta ideia sintetiza, talvez, o núcleo do projeto da Aufklärung como maioridade, ou seja, para que efetivamente ocorra a Ausgang da menoridade para a maioridade, é preciso redistribuir a relação entre governo de si e governo dos outros. Embora Foucault não esclareça devidamente o que entende por "redistribuir", podemos intuir, considerando suas reflexões filosóficas mais amplas sobre a política, que ele tem em mente uma relação de natureza ética entre governo de si e governo dos outros. Ética, no sentido de que a condição primeira do governo de si passa pela atitude do indivíduo de não querer ser nem covarde, nem preguiçoso; do governo dos outros, de não subjugar o indivíduo. Redistribuição pode significar, então, primeiramente, que o problema não reside só num dos dois polos e, segundo, que o enfrentamento do aspecto viciado dessa relação passa pela compreensão do papel normativo, de natureza éticopedagógica, que tanto o governo de si como o governo dos outros desempenham na constituição da "boa" sociabilidade humana. ${ }^{12}$

Não precisamos seguir reconstruindo em detalhes as páginas finais dedicadas por Foucault, na segunda hora da aula de 5 de janeiro, à exegese do texto kantiano, pois o que temos desenvolvido até aqui já nos permite alcançar o ponto para analisar o segundo aspecto da dimensão pedagógica que está relacionada com o processo da Aufklärung como maioridade. Tal aspecto refere-se, conforme já afirmado acima, à questão do governo dos outros. Mas qual é a dimensão eminentemente pedagógica inserida na questão do "governo dos outros"? Ela contém vários fatores, dos quais vamos comentar apenas dois.

\footnotetext{
${ }^{12}$ Na sequência das aulas do curso de 1983, Foucault toma, como se sabe, a parrhesía como ponto de partida para criticar a "relação viciada" entre governo de si e governo dos outros. Nesse sentido, a questão decisiva, que não é objeto deste ensaio e que, certamente, merece um estudo à parte, consiste em saber em que termos a coragem de dizer a verdade pode ser referência normativa para "redistribuir" a relação entre governo de si e governo dos outros.
} 


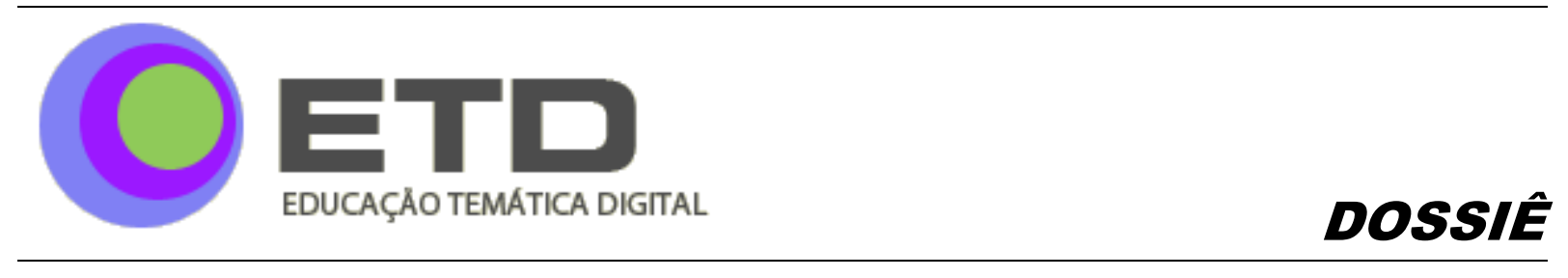

O primeiro deles diz respeito ao fato de que o governo de si, sobretudo quando se trata do problema do processo formativo-educacional das novas gerações - e pensamos que a questão da Aufklärung como maioridade tem a ver, antes de tudo, com isso -, exige o governo dos outros. Ou seja, o trabalho pedagógico que o indivíduo precisa fazer sobre si mesmo, o cultivo permanente que ele precisa realizar sobre si mesmo, também é resultado do próprio trabalho pedagógico que os outros, os mais velhos, exercem sobre ele. Este é o primeiro fator. $\mathrm{O}$ segundo fator, vinculado ao primeiro, refere-se à própria natureza do trabalho pedagógico exercido pelos outros sobre o indivíduo. Ela pode ser esclarecida pela própria natureza que constituiu, segundo Foucault, a relação mais ampla, envolvendo aspectos éticos e políticos, entre o si mesmo e os outros. Considerando que Foucault a compreende como uma relação de governo e de direção, o trabalho pedagógico exercido pelos outros sobre o indivíduo assume a natureza de um governo e de uma direção e, obviamente, o problema relevante gira em torno de saber o modo como é exercido tal governo ou tal direção. ${ }^{13}$

Resumindo, temos dois aspectos nitidamente pedagógicos implicados no problema do processo da Aufklärung como maioridade: trabalho pedagógico do indivíduo sobre si mesmo e trabalho pedagógico dos outros sobre o indivíduo. Se formos analisar mais a fundo a questão, podemos observar que os dois aspectos pedagógicos implicados nada mais significam do que a relação pedagógica pensada a partir dos dois polos que a constituem, a saber, o do educando e o do educador e, sobretudo, a partir do modo como eles interagem. ${ }^{14}$ Sendo assim, se a dimensão filosófica da Aufklärung como maioridade se deixa pensar como relação entre governo de si e governo dos outros, sua dimensão propriamente pedagógica apresenta-se, por sua vez, nos termos de que o governo de si, quando relacionado ao educando, precisa da direção de outros (do educador) para ser formado.

Vista nesta perspectiva, a problemática filosófica da Aufklärung como maioridade tem a ver diretamente com uma problemática pedagógica: se a questão decisiva é como poder

\footnotetext{
${ }^{13}$ Como foi afirmado na nota anterior, na sequência do curso de 1983, Foucault busca na parrhesia aspectos normativos de tal exercício, mostrando que a relação não viciada entre governo de si e governo dos outros começaria pela coragem de dizer a verdade.

${ }^{14}$ Mencionamos aqui uma discussão, já em andamento no Brasil, que busca pensar a educação (ou seja, fenômenos educacionais e escolares no sentido mais amplo) a partir das ferramentas conceituais do último Foucault. Como parte desta discussão, destacam-se o recente livro de Carvalho (2010) e o artigo ainda não publicado de Pagni (2010).
} 


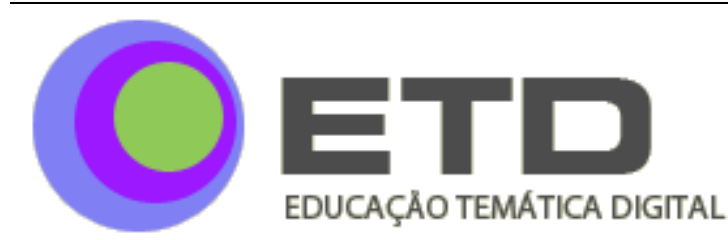

DOSSIÉ

fazer uso de sua própria razão e se ninguém nasce sabendo fazê-lo, então todos precisam passar por um processo formativo-educacional, a começar já, sobretudo na primeira infância. É isso, então, que caracteriza o fato eminentemente pedagógico da condição humana, a saber, o ser humano encontra-se, em seu estado inicial, sob a direção de outros, precisando de seus cuidados. Nesse sentido, sua saída dessa condição de menoridade inicial para uma progressiva maioridade exige um trabalho pedagógico concentrado e bem dirigido de outros (educadores) sobre ele mesmo (educando). Ora, é esta condição eminentemente humana de necessidade de aprendizagem que, ao mesmo tempo, estabelece o primado pedagógico intrínseco ao processo da Aufklärung como maioridade. Tal primado se justifica porque a maioridade almejada só pode ser alcançada por meio de um bom governo (de uma boa direção) dos outros, e isso significa dizer, em termos claramente pedagógicos, que o educador precisa exercer bem seu papel de governante, para que o educando possa fazer bom uso de sua própria razão. ${ }^{15}$

O primado pedagógico presente na questão da Aufklärung mostra-se, portanto, no fato de que nenhum ser humano pode sair por si só, sem um processo formativo-educacional, de seu estado de menoridade. Por necessitar inicialmente do governo de outros para, primeiro, poder alcançar progressivamente o governo de si mesmo e, depois, também poder bem governar os outros, é que o ser humano necessita de educação.

Concluindo, podemos afirmar que a questão que, de fato, nos motivou a parafrasear detalhadamente a exegese foucaultiana do texto de Kant nada mais foi do que compreender o que significa o esclarecimento como maioridade pedagógica. No texto kantiano há uma preocupação pedagógica de fundo, embora implícita, a qual se torna mais explícita pelo modo original e criativo com o qual Foucault interpretou o ensaio "Was ist Aufklärung?". Pensamos que é possível oferecer, depois deste percurso, uma resposta, ainda

15 É interessante notar que este tema do educador como bom governante, considerado como condição indispensável para que o educando alcance sua maioridade, não é central somente à Aufklärung kantiana, como também sustenta o esboço do projeto de uma educação natural e social, largamente desenvolvido por JeanJacques Rousseau no Emílio ou da Educação. Coordenamos, recentemente, um projeto coletivo de investigação que buscou tratar do tema do educador como governante nos cinco livros que compõem a referida obra de Rousseau. Os resultados dessa investigação podem ser encontrados no livro Filosofia e educação no Emílio de Rousseau: o papel do educador como governante, por nós coordenado e a ser publicado em breve pela Editora Átomo \& Alínea (DALBOSCO, 2011a). De outra parte, tratamos dos cuidados do adulto relacionados à primeira infância, num outro livro, intitulado Paradoxos da educação natural em Rousseau: das necessidades da criança $e$ dos cuidados do adulto, a ser publicado em breve pela Editora Cortez (DALBOSCO, 2011b). Neste trabalho nos concentramos em analisar a tensão entre necessidades da criança e cuidados do adulto, tomando como referência o primeiro livro do Emílio. 


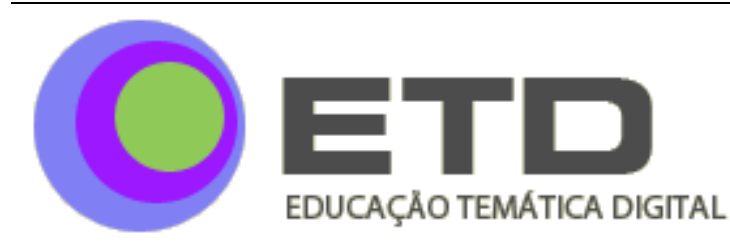

DOSSIÉ

que muito provisória, à questão do esclarecimento como maioridade pedagógica: a saída do estado de menoridade do qual somos culpados passa pela superação da relação de preguiça e de covardia que estabelecemos ou podemos estabelecer com nós mesmos.

No entanto, tal superação só pode ocorrer - sobretudo, quando se tem em mente a relação do educador com o educando, do adulto com a criança e, enfim, o problema da formação de novas gerações - pelo bom exercício do governo que os outros exercem sobre nós mesmos. Isso significa dizer que o uso autônomo da própria razão que cada um de nós pode alcançar precisa contar, além da coragem de pensar por conta própria, com o trabalho formativo-educacional que os outros, os mais velhos, fazem ou deixam de fazer conosco. Ou seja, a coragem de pensar por conta própria, que é o aspecto decisivo do governo de si, também é resultado do trabalho pedagógico do bom governo que os outros exercem sobre nós. Isto é, então, o que denominamos de primado pedagógico inerente à problemática da Aufklärung como maioridade.

\section{REFERÊNCIAS}

BAHR, E. (Hrsg). Was ist Aufklärung? Kant, Erhard, Hamann, Herder, Lessing, Mendelssohn, Reim, Schiller, Wieland. Stuttgart: Reclam, 1996.

CARVALHO, A. F. Foucault e a função educador-sujeito e as experiências de subjetividades ativas na formação humana. Ijuí: Unijui, 2010.

DALBOSCO, C. A. (Org.). Filosofia e educação no Emílio de Rousseau: o papel do educador como governante. Campinas: Editora Átomo; Alínea, 2011a. (No prelo).

Paradoxos da educação natural em Rousseau: das necessidades da criança e dos cuidados do adulto. São Paulo: Cortez, 2011b. (No prelo).

Pragmatismo, teoria crítica e educação. Campinas: Autores Associados, 2010.

EWALD, F. Die Philosophie als Akt. Zum Begriff des philosophischen Akts In: ERDMANN, E.; FORST, R.; HONNETH, A. (Hg.). Ethos der Moderne: Foucaults Kritik der Aufklärung. Frankfurt; New York: Campus Verlag, 1990. p. 87-100.

FOUCAUlT, M. A Hermenêutica do sujeito. Trad. Márcio A. da Fonseca e Salma T. Muchal. São Paulo, SP: Martins Fontes, 2004. 


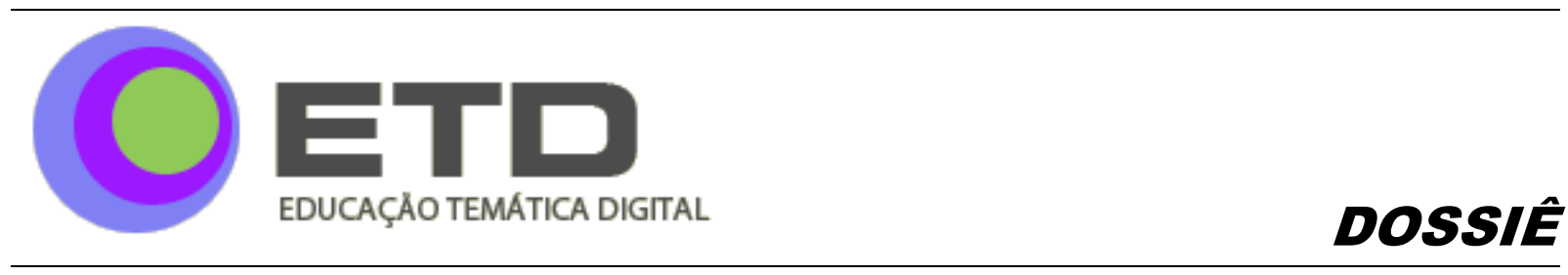

. As palavras e as coisas: uma arqueologia das ciências humanas. Trad. Salma T. Muchal. São Paulo, SP: Martins Fontes, 1990b.

. Ditos e escritos: estratégia, poder-saber. Trad. Vera Lucia A. Ribeiro. Rio de Janeiro, RJ: Forense Universitária, 2006. (v.4).

El gobierno de si y de los otros. Trad. Horacio Pons. Buenos Aires: Fondo de Cultura Económica, 2009.

Was ist Aufklärung? In: ERDMANN, E.; FORST, R.; HONNETH, A. (Hg.). Ethos der Moderne: Foucaults Kritik der Aufklärung. Frankfurt; New York: Campus Verlag, 1990a. p. 35-54.

KANT, I. Werke in sechs Bänden. Darmstadt: WBG, 1998. (v.2 - Kritik der reinen Vernunft; v.4 - "Was ist Aufklärung?”)

PAGNI, P. O cuidado de si em Foucault e as suas possibilidades na educação: algumas considerações. Marília, 2010. (Texto inédito).

RABINOW, P.; DREYFUS, H. Was ist Mündigkeit? Habermas und Foucault über 'Was ist Aufklärung?. In: ERDMANN, E.; FORST, R.; HONNETH, A. (Hg.). Ethos der moderne: Foucaults kritik der Aufklärung. Frankfurt; New York: Campus Verlag, 1990, p. 55-69.

Michel Foucault: uma trajetória filosófica: para além do estruturalismo e da hermenêutica. Rio de Janeiro, RJ: Forense Universitária, 1995.

TERRA, R. Passagens: estudos sobre a filosofia de Kant. Rio de Janeiro, RJ: Editora da UFRJ, 2003.

VEIGA-NETO, A. Foucault \& Educação. Belo Horizonte: Autêntica, 2003. 


\section{Cláudio A. Dalbosco}

Possui graduação em Filosofia pela Universidade de Passo Fundo (UPF/RS), mestrado em Filosofia na PUCRS e doutorado em Filosofia na Universidade de Kassel/Alemanha; Atualmente é professor no Curso de

Filosofia e no Programa de PósGraduação em Educação da UPF/RS e pesquisador do CNPq;

É autor dos livros Ding an sich und

Erscheinung: Perspektiven des transzendentalen Idealismus bei Kant, (Königshausen \& Neumann, 2002); Pedagogia Filosófica: Cercanias de um diálogo (Editora Paulinas, 2007); Moralidade e educação em Kant, em co-autoria com Heinz Eidam (Editora UNIJUÍ, 2009); Pragmatismo, teoria crítica e educação, (Autores Associados, 2010);

Paradoxos da educação natural em Rousseau,

(Editora Cortez, 2010 - no prelo)

E-mail: vcdalboso@hotmail.com

Recebido em: 18/10/2010

Publicado em: 30/12/2010 